\title{
MAPEAMENTO COLABORATIVO: UMA ALTERNATIVA PARA A OBTENÇÃO DE MAPAS DIGITAIS PARA APLICAÇÓES EM TRANSPORTES
}

\author{
Renato da Silva Lima ${ }^{1}$ \\ Livia Alvim Borher ${ }^{2}$ \\ André Carvalho Silveira ${ }^{3}$ \\ Josiane Palma Lima ${ }^{4}$
}

\begin{abstract}
Resumo: O Brasil, assim como outros países emergentes, enfrenta a carência de dados espaciais disponíveis para o desenvolvimento e uso das geotecnologias em aplicações de transportes. Como alternativa, apresentase o mapeamento colaborativo, que a partir de uma metodologia bem definida permite dividir a difícil tarefa de mapear a malha viária brasileira entre voluntários. O objetivo desse trabalho é ilustrar como o mapeamento colaborativo pode ser utilizado para a obtenção de mapas digitais para aplicaçôes em transportes. Todas as fases de desenvolvimento de um mapa municipal de Itajubá-MG foram detalhadas, no âmbito do Projeto Tracksource, maior iniciativa brasileira conhecida de mapeamento colaborativo. Os resultados comprovaram, a partir da conclusão do mapa de Itajubá, que o mapeamento colaborativo é uma opção concreta para obtenção de mapas digitais para aplicações em transportes, especialmente num país como o Brasil, com dimensões continentais e com defasagem na disponibilização pública desse tipo de informação.
\end{abstract}

Palavras-chave: Mapeamento Colaborativo; Sistema de Informação Geográfica; Infra-estrutura de Transporte.

Abstract: Brazil, as other emerging countries, faces the lack of spatial data available to the development of the geotechnology in transport applications. As an alternative, collaborative mapping is introduced. Collaborative mapping is a concept that uses a very defined methodology, which allows volunteers to share the hard work of mapping Brazilian roads networks. This paper aims to illustrate how the collaborative mapping can be useful to achieve digital maps to applications in transport. All the steps to construct the municipal map of Itajubá-MG were detailed, in terms of the Tracksource Project, the bigger known initiative of collaborative mapping in Brazil. The results has proved, that the collaborative mapping is a solid option to gathering of digital maps to transport applications, specially in a country like Brazil, with continental dimensions and lag in public availability of this type of information.

Keywords: Collaborative Mapping; Geographic Information System; Transportation Infrastructure.

\section{INTRODUÇÃO}

A tecnologia geográfica se firma como ferramenta útil na gestão e suporte a diversas áreas da atividade humana. Logística, transportes, planejamento urbano, gestão ambiental, geomarketing, saúde pública, controle de desastres naturais, são algumas das áreas onde a informação geográfica pode ser aplicada.

O desenvolvimento da tecnologia espacial, que trata a informação levando-se em conta a geografia, já apresenta maturidade suficiente para ofe-

\footnotetext{
1 Universidade Federal de Itajubá, Instituto de Engenharia de Produção e Gestão, rslima@unifei.edu.br

2 Universidade Federal de Itajubá, Instituto de Engenharia de Produção e Gestão, borher@gmail.com

3 Universidade Federal de Itajubá, Instituto de Ciências Exatas, andrecarvalhosilveira@gmail.com

4 Universidade Federal de Itajubá, Instituto de Engenharia de Produção e Gestão, jplima@unifei.edu.br
} 
recer funcionalidades que potencializam a abrangência e precisão da ação profissional em diversas áreas, principalmente a partir da década de 1990, com a popularização dos Sistemas de Informações Geográficas (SIG).

Entretanto, é comum que o trunfo das geotecnologias esbarre na falta de dados geográficos, às vezes não coletados e muitas vezes desatualizados, que impedem resultados precisos e confiáveis.

Estatísticas de tráfego rodoviário, levantamentos topográficos e geodésicos, informações do clima, uso e ocupação do solo, dados censitários, são exemplos de dados espaciais importantes para análises cotidianas que podem ser assistidas por SIG. O Brasil é carente desse tipo de informação, sendo que muitas vezes sua coleta está condicionada a esforços isolados, sejam de prefeituras, universidades ou empresas que buscam levantar insumos para atender demandas eminentes (Lima et al., 2009).

Esse cenário se repete para aplicações dos SIG em Transporte, onde diversas rotinas como cálculo de distâncias mínimas em rede, localização de instalaçôes, roteirização de veículos, entre outros, demandam mapas viários, pontos de interesse, limites municipais em formato digital com precisão e atualização adequada para uso.

Ao se falar em transporte, especificamente em logística, geralmente têm-se duas formas de se obter dados para apoiar a inteligência geográfica na área: dados públicos disponibilizados por organizações como Prefeituras e Departamento Nacional de Infra-estrutura de Transportes; e dados privados oriundos de produtos e serviços de empresas privadas. Segundo Ferreira et al. (2007), estas instituições, embora disponibilizem grande quantidade de dados, normalmente disponibilizam informações desatualizadas, não coincidentes ou até mesmo erradas, havendo a necessidade de especialização dos dados.

É comum que os dados públicos sejam disponibilizados em formato digital PDF o que não satisfaz às funcionalidades e análises assistidas por SIG. Esses dados não estão aptos para edição e manipulação plena e, muitas vezes, é preciso classificar a informação e organizá-la em modelos e formatos de dados compatíveis aos SIG. Já os dados oferecidos por empresas em forma de produtos e serviços são caros e muito restritos às áreas de alto valor comercial e às grandes regióes metropolitanas, deixando a maioria do país descoberto e prejudicando estudos e trabalhos localizados fora das áreas cobertas.

Nesse contexto surge uma nova alternativa para a obtenção de dados espaciais viários, através do chamado mapeamento colaborativo. Este sistema acompanha a tendência de informaçôes geográficas obtida por contribuição voluntária (volunteered geographic information, VGI), que envolve a necessidade de motivar, viabilizar e integrar simples contribuições de diversas pessoas a dados detalhados e sofisticados, mantidos por instituições públicas e privadas, utilizando a internet (Davis et al., 2009).

Assim, um mapeamento colaborativo em transporte é um levantamento da malha viária de uma região realizada por algum voluntário que pode ser profissional ou amador e que posteriormente é disponibilizado de forma que outros interessados possam fazer uso do mapa elaborado. Os mapas colaborativos são geralmente criticados pela falta de confiança na informação contida, justamente pela dificuldade de se garantir que os dados provindos de inúmeras fontes voluntárias possuam qualidade satisfatória à requerida pela aplicação. Porém, novas tendências na área aplicam o uso de metodologias no mapeamento a fim de garantir determinado grau de qualidade em mapas colaborativos.

O Projeto Tracksource (Tracksource, 2009) é um exemplo dessa tendência, consiste na iniciativa de construir mapas viários do Brasil para o uso gratuito em aparelhos GPS Garmin®. O crescimento exponencial do Projeto Tracksource a partir de 2002, em número de usuários, voluntários e área mapeada, sugere que o mapeamento colaborativo bem estruturado pode ser uma valiosa fonte de dados geográficos para aplicações em transporte.

O objetivo desse trabalho é ilustrar como o mapeamento colaborativo pode ser utilizado para a obtenção de um mapa digital para aplicações em transportes, diretamente, para navegação veicular, e indiretamente, como um formato intercambiável para os SIG. Para tanto, será detalhado todas as fases de desenvolvimento de um mapa municipal, de Itajubá, MG, no âmbito do Projeto Tracksource.

Assim, após essa breve introdução, a seção 2 apresenta a fundamentação teórica dos diversos temas relacionados ao trabalho. $\mathrm{O}$ desenvolvimento do trabalho é apresentado na seção 3, seguido das conclusões sobre o mapeamento colaborativo na seção 4 e das referências bibliográficas utilizadas. 


\section{FUNDAMENTAÇÃO TEÓRICA}

\subsection{MAPEAMENTO DIGITAL}

A necessidade de conhecer uma região e grafar todos os elementos relevantes a uma atividade do homem vem de muito tempo, sendo que os mapas nos acompanham desde então. Segundo Santos (2001), um mapa é a forma mais familiar de representar dados geográficos, sendo constituído por pontos, linhas e polígonos, de acordo com determinado sistema de coordenadas. Com a era da informação e popularização do uso de computadores pessoais, surgem os mapas eletrônicos em formato digital.

Assim como os outros tipos de informação digital, os mapas digitais apresentam como principais vantagens sua fácil e eficiente construção, edição e armazenamento. Além disso, com os Sistemas de Informação Geográfica os mapas digitais passam a ser processados em modelos matemáticos robustos e algoritmos heurísticos, potencializando a capacidade do decisor analisar situações relacionadas à geografia.

O mapeamento digital, de forma geral, é o levantamento de informações espaciais e tabulares representado em formato digital, respeitando projeçōes geodésicas, datum e sistemas de coordenadas (Charlier et al., 2004). Um mapa digital pode ser apenas visualizado ou também processado pelos SIG. O mapeamento digital, segundo Andrade et al. (2003), normalmente é visto apenas como uma melhoria na exibição das ocorrências, mas desempenha um papel primordial no processo de apresentação, pesquisa e análise.

Mapas digitais podem, então, ser aplicados aos mais variados estudos relacionados ao espaço, como: mapeamento da malha viária de um país, mapeamento dos clientes e fornecedores de uma cadeia produtiva, mapeamento dos crimes de um município, mapeamento do alastramento de um vírus, estudo de potencialidades do ambiente (Valladares et al., 2004), entre vários outros tipos de mapeamento que podem ser feitos digitalmente.

\subsection{MAPEAMENTO COLABORATIVO E PROJETO TRACKSOURCE}

O mapeamento colaborativo é quando mais de uma iniciativa de mapeamento ocorre na mesma região e ambos os trabalhos se comu- nicam entre si e contribuem uns aos outros. No mapeamento colaborativo existe a troca de dados geográficos, mas nem sempre a metodologia e os equipamentos utilizados são os mesmos.

A falta de modelos conceituais comuns acarreta problemas na troca destes dados, como distorção dos mesmos, comprometimento de qualidade da informação, possível perda de definições de atributos e georeferenciamento (Lima et al., 2001). O maior desafio para os participantes do mapeamento colaborativo é conseguir com que o dado coletado por um participante seja compatível com os demais de forma com que a ação do grupo seja maior do que a soma de cada ação individual.

Por mais que o mapeamento de cada participante da colaboração ocorra nos mesmos limites geográficos que os demais muitos fatores podem levar a não compatibilidade direta entre os trabalhos, são eles: sistema de projeção geográfica, precisão das coordenadas, escala, elementos geográficos abrangidos, classificação da informação, entre outros.

Para evitar conflitos entre os trabalhos de todos os participantes diante dos fatores citados é comum o uso da padronização das técnicas de mapeamento, ou seja, fixar convençôes a serem seguidas por todos os participantes. Dessa forma é possível antecipar-se diante dos possíveis erros de compatibilidade.

A escolha da técnica e dos demais detalhes a serem adotados como padrão deve ser criteriosa, a fim de garantir a interoperabilidade entre o mapeamento de todos os participantes e a qualidade final da união dos trabalhos em um só produto.

Outras formas de mapeamento colaborativo podem ocorrer. Por exemplo, é cada vez mais comum sites com serviços de webmapping, ou seja, mapas digitais na Internet. Ao utilizar o serviço de mapa oferecido por esses sites, o internauta pode contribuir acusando erros e/ou melhorias.

A tarefa de mapear com qualidade e abrangência acaba sendo muito pesada para as empresas privadas e até mesmo para os órgãos públicos ligados ao espaço brasileiro. O mapeamento colaborativo permite que o grande e importante trabalho de mapear o Brasil seja dividido entre todos os interessados.

O Projeto Tracksource, maior iniciativa brasileira conhecida de mapeamento colaborativo, conta atualmente conta com 1351 municí- 
pios mapeados em 25 estados do Brasil. Assim, o projeto cobre aproximadamente $25 \%$ do país, incluindo regiões metropolitanas e regiōes mais afastadas dos grandes centros. Muitos mapas vendidos comercialmente não apresentam tal cobertura e, além disso, conta também a favor dos mapas colaborativos uma atualização geralmente mais freqüente.

Os mapas do Projeto Tracksource são atualizados mensalmente. As estatísticas de acesso ao site do projeto mostram que a média de visitação diária tem aumentado desde agosto de 2008, sendo que nos últimos meses este valor é de cerca de 3000 visitas diárias.

\subsection{QUALIDADE E ACESSIBILIDADE DE DADOS ESPACIAIS}

Segundo Vinhas (2006), dados geográficos são informações que possuem uma dimensão espacial, ou localização, diretamente ligada ao mundo geográfico real. Dados censitários, limites municipais, diretório nacional de endereços - DNE, imagens de satélite, hidrografia, relatórios estatísticos oferecidos pelo INPE e outros organismos do governo são informações espaciais disponíveis.

Esses dados combinados a outros mais específicos podem compor analises espaciais que inferem tanto em soluções importantes para o setor público no atendimento a população, quanto em produtos que podem ser comercializados pelas empresas privadas.

Nesse sentido, quanto mais dados espaciais estiverem acessíveis mais se fomenta o desenvolvimento econômico, o bem-estar social e o conhecimento tecnológico-científico. Para isso é preciso não só o investimento em coleta de dados geográficos, mas também em manutenção dos dados coletadas. Atualmente muitas funcionalidades baseadas em tecnologia geográfica não são aplicáveis devido a falta de insumos, os dados espaciais.

Tomando os transportes como exemplo, acidentes, congestionamento, custos, impacto ambiental, todos esses males dos grandes centros poderiam ser tratados com inteligência geográfica, mas os ganhos dessa tecnologia são barrados pela falta de sensores de trânsito, condições das vias, mapeamento viário, plantas urbanas, dados demográficos e econômicos, entre outros dados necessários.

\subsection{APLICAÇŌES DE SIG EM TRANSPORTES E LOGÍSTICA}

A relação entre os SIG e a Logística é bem estreita, uma vez que essa está, de alguma maneira, relacionada com questóes envolvendo o transporte ou a transmissão de materiais, serviços e informações ao longo do espaço geográfico (Lima et al., 2009). Assim é possível abordar atividades como escoamento de produtos por centros de distribuição, alocação de alunos em escolas e creches, atendimento dos postos de saúde, cobertura do corpo de bombeiros, rotas de coleta de lixo etc. (Enomoto e Lima, 2007).

A especialidade de alguns sistemas e a utilização de modelos incorporados projetados especificamente para a análise e a gestão dos sistemas de transporte dão origem aos chamados SIG-T (Sistemas de Informações Geográficas para Transportes). O SIG-T possui funções específicas para problemas de roteirização (particularmente o problema do caixeiro viajante e procedimentos relacionados), algoritmos de localização de atividades e alocação de clientes (modelos location-allocation) (Mapa et al., 2007).

Os SIG-T usam como principal recurso para criação de cenários de análise os mapas viários de determinada região. Esses dados se apresentam em forma de vetores que indicam as vias, suas ligações e direção, além de apresentar informações tabulares relacionadas a cada vetor. Essas informaçóes relacionam nome de logradouro, numeração, tipo e condições da via, velocidade da via, restrições de manobra, hierarquia entre outros parâmetros essenciais para o planejamento em Transportes.

É esse o tipo de informação que o Projeto TrackSource visa oferecer como insumo de navegação em aparelhos GPS, bem como recurso para análise em SIG.

\subsection{GPS, ORIENTAÇÃO VEICULAR E ROTEIRIZAÇÃO}

Segundo Segantine (2005), o Sistema Global de Posicionamento (GPS) permite aos usuários determinar sua posição expressa em latitude, longitude e altura em função das coordenadas cartesianas $\mathrm{X}, \mathrm{Y}$ e Z em relação ao centro de massa da Terra. Isso se dá em função da comunicação entre satélites receptores e emissores de sinais que trocam dados com os chamados aparelhos GPS 
portáteis e enviam ao usuário do aparelho sua localização no globo.

Atualmente o GPS pode ser encontrado em diversos tipos de aparelhos portáteis como celulares, navegadores veiculares, rastreadores e equipamentos técnicos de levantamento em campo de diferentes precisões. Dentre estes, os tradicionais aparelhos de GPS são mais vantajosos para usuários que buscam destinos mais afastados e menos conhecidos, por oferecerem a possibilidade da aquisição de uma base de mapas (Martoni e Varajão, 2008).

Os navegadores veiculares com GPS são interessantes por atualizar automaticamente a localidade em que o carro se apresenta no mapa. Dessa maneira o próprio aparelho pode inferir sugestôes e informações relevantes ao condutor sem o mesmo ter que fazer a leitura do mapa, a chamada navegação veicular.

A orientação veicular compreende todo o tipo de informação passada ao condutor e aos tripulantes de um veículo durante a viagem. Através da orientação veicular o condutor pode ter acesso a diversos tipos de informação, desde a visualização das vias do entorno, indicação de rota, pontos de referência, opções de manobras permitidas e outras informaçōes adicionais relevantes ao objetivo da viagem: pontos turísticos, atendimento médico, postos policiais, pontos de coleta, pontos de parada etc.

Graças ao GPS, é possível que o motorista visualize os arredores do ponto em que dirige sem nunca ter estado naquela área antes. Atualmente começam a se tornar populares serviços que informam a situação da navegação em tempo real, como intensidade do trânsito, impedimento de vias e acidentes.

Entretanto, o principal objetivo da navegação veicular é roteirização. Ao se fixar um ponto de origem e um ponto de destino, existem varias alternativas para se traçar o caminho mínimo através das vias disponíveis entre os dois pontos fixados. Nem sempre o caminho que envolve a menor distância percorrida é o mais interessante. Por exemplo, um caminho mais longo pode ser mais rápido por apresentar menor trânsito, ou então outro caminho pode ser mais interessante por apresentar vias mais seguras e adequadas ao tipo de veículo utilizado. Ainda assim pode-se preferir outra rota por envolver um ponto de interesse entre origem e destino.
Segundo Cunha (2000) a roteirização pode ser definida como um meio de determinar roteiros ou seqüências de paradas a serem cumpridos, a fim de se utilizar e atender pontos geograficamente dispersos, em locais predeterminados. Os problemas de roteirização, por si só exemplificam bem como um SIG pode facilitar o trabalho de profissional ajudando a minimizar o custo de um transporte. Existem disponíveis desde técnicas heurísticas de roteirização como a Busca Tabu, muito utilizada em SIG comerciais, até modelos matemáticos otimizantes mais robustos.

\subsection{GPS TRACKMAKER (GTM)}

O GPS Trackmaker (GTM) é um software gratuito de manipulação de informações geográficas que permite ao usuário criar facilmente seus próprios mapas. De fácil aprendizagem e manuseio, este programa tem sido de fundamental importância na criação de mapas para GPS no Brasil e em outros países.

Atualmente é o programa gratuito mais completo para GPS. Possui compatibilidade com mais de 100 modelos de GPS, sendo utilizado principalmente em aparelhos Garmin. O programa permite a conexão entre o GPS e o computador a fim de se ter a troca de dados entre ambos aparelhos.

O GTM possui funções de reconhecimento de dados como pontos, tracks (trechos) e rotas, e permite ao usuário a edição destas informações, através de diversas funções. Assim, é possível ter a criação do mapa, sua formatação e adição de outras informaçôes extras. Podem-se incluir imagens digitais ou diretamente de programas como o Google Earth, a fim de se criar o mapa.

Outra opção é a inclusão de dados de altitude para pontos e para vias, além de ser possível incluir valores de velocidade e calcular o comprimento das vias. A versão profissional disponibiliza opções mais avançadas como cálculos de área, compatibilidade com AutoCAD, cálculo de distâncias horizontal e diferenças de altitudes etc.

\section{ESTUDO DE CASO: MAPEAMENTO COLABORATIVO DO MUNICÍPIO DE ITAJUBÁ, MG}

A fim de exemplificar todo o processo de desenvolvimento colaborativo de um mapa digital 
viário, será aqui apresentado o caso do município mineiro de Itajubá, realizado no contexto do Projeto Tracksource.

O mapeamento do Brasil no âmbito do projeto é dividido em estados, regiōes e municípios. Assim, quando um usuário, voluntariamente, se oferece para coordenar o mapeamento de uma cidade, passa a ser chamado de desenvolvedor, e recebe do compilador estadual, um outro voluntário desenvolvedor, um mapa com o limite municipal da cidade a ser mapeada.

Fica a cargo do desenvolvedor garantir que o município seja mapeado conforme os padrões do projeto e cabe ao compilador garantir que não ocorram conflitos entre vetores de vias e rios e entre municípios vizinhos. As fases que dizem respeito ao desenvolvedor são descritas nos itens a seguir.

\subsection{OBTENÇÃO DE DADOS}

O mapeamento digital de redes viárias consiste basicamente em armazenar a geografia de cada via, bem como informações referentes a cada trecho da mesma. Outros elementos presentes nos arredores das vias e relevantes também devem ser capturados, como áreas políticas, pontos de pedágio, lugares de valor turístico/econômico, entre outros fatores que contribuem para o auxílio do motorista durante a navegação.

Para ter acesso às informações das vias e dos demais elementos a serem mapeados pode-se utilizar duas alternativas: coleta de dados em campo, ou coleta de dados através de imagens de satélite e fotos aéreas.

A primeira consiste no levantamento em campo com aparelho GPS da área a ser mapeada, coletando as coordenadas geográficas das vias de forma direta e precisa. No entanto, essa coleta em campo apresenta algumas desvantagens, como a necessidade de um aparelho GPS, tempo gasto de deslocamento até o local a ser mapeado e uma possível indisponibilidade do sistema em alguns locais, devido à dificuldade de recepção de sinal dos satélites.

Já o uso de imagens de satélite e fotos aéreas permite o acesso à regiōes mais remotas e, por dispensar a necessidade de deslocamento até às vias a serem mapeadas, se torna uma opção muito viável em razão da disponibilidade a custo zero, como é o caso do Google Earth. Entretanto, essa abor- dagem envolve mais um passo adicional que é o georeferenciamento das imagens.

Caso se tenha a coleta de dados pelos dois métodos, é necessário fazer o georreferenciamento segundo os dados coletados pelo GPS, uma vez que sua precisão é maior que a do Google Earth. Lima et al., (2009) afirmam que o uso de imagens do software Google Earth para a obtenção de mapas viários digitais para aplicaçôes em transportes é adequado, já que a precisão encontrada para este software fica na casa de 20 metros.

\subsection{VETORIZAÇÃO}

Após a fase de coleta de dados, deve-se transcrever as informações geográficas e tabulares coletadas em campo. Para isso utiliza-se o software GTM, que permite a edição de dados geográficos (através de representações geométricas básicas de ponto, linha e polígono).

Para transferir os dados do GPS para o GTM, pode-se utilizar o próprio GTM em sua versão profissional ou um software intermediário, o MapSource, que serve como interface GPS/ Computador para aparelhos Garmin.

A vetorização começa quando se tem todos os dados coletados disponível no GTM, assegurando que os dados espaciais contidos no GPS serão tratados pelo computador com o mesmo sistema de projeção (no caso em questão, WGS84, fuso 23).

Caso não se tenha a disponibilidade de um GPS, devem-se desenhar as vias em sua localização correta, utilizando as imagens coletadas com o Google Earth.

O software GTM possui uma ferramenta que permite este desenho, sendo possível desenhar, além das ruas, outras entidades como rios, linhas férreas, curvas de nível, praças e prédios, como indústrias, por exemplo. Todas as vias, que são representadas por linhas, devem se conectar para formar a malha viária. Portanto, é de extrema importância verificar no mapa se isso acontece. Para desenhar estas vias deve-se, após colher as imagens do Google Earth, utilizar a ferramenta "lápis" para traçar linhas em cima de partes das fotos que sejam ruas.

Mesmo que se tenha a coleta de dados com o GPS, estes ainda devem ser ajustados no GTM. Deve-se utilizar o mínimo possível de segmentos para a representação das ruas, já que eles influem no tamanho e complexidade do mapa, dificultan- 
do o posterior trabalho de roteirização do aparelho GPS. Assim, na representação de uma face de quadra, por exemplo, o ideal é que essa rua seja desenhada no GTM apenas como uma reta representada por um ponto inicial e final, sem segmentação intermediária.

Nesta fase inicial, as vias são a prioridade para o desenvolvimento do voluntário, uma vez que são estas vias que permitem ao aparelho GPS realizar a navegação veicular, em detrimento de outras entidades que serão posteriormente incorporadas ao mapa (lagos, rios, praças etc.).

As entidades que compõem o mapa, segundo os padrōes do projeto podem ser pontos, linhas e polígonos. Têm-se entidades de pontos para representar prédios, de linha para representar vias, e polígonos para representar áreas verdes, por exemplo. Em alguns casos, pontos de interesse são transformados em polígonos para melhor visualização durante a navegação veicular.

A Figura 1 apresenta um exemplo de vetorização de uma parte do mapa de Itajubá, contendo vias, praças (polígonos em verde), rios e outras entidades, como prédios (em cinza).

\subsection{COMPLEMENTAÇÃO DE ATRIBUTOS}

Após o processo de coleta de dados geográficos, tem-se a formatação dos atributos, os chamados dados tabulares ou alfanuméricos. É importante nomear corretamente cada uma destas entidades, de acordo com o padrão fixado pelo Projeto Tracksource, desde a especificação de tipo e nome da via até a definição do seu grau de hierarquia entre as demais vias do município.

O padrão do projeto impóe normas e restrições quanto à nomenclatura das entidades e indica qual símbolo deve ser utilizado para cada entidade. Um exemplo é pode ser a representação de uma Universidade, que deve ser representada por uma construção, e em seu nome deve ter a sigla da instituição, seguida da palavra Universidade.

Outros tipos de restrições são quanto a abreviações, acentuação, símbolos dos pontos de interesse e, caso sejam necessários, comentários. A Figura 2 ilustra esse procedimento, exibindo um ponto de interesse ao longo da via representando uma universidade UNIFEI. Também é traçado um polígono que revela a área da universidade, e seus respectivos atributos aparecem padronizados como mostra a janela auxiliar.

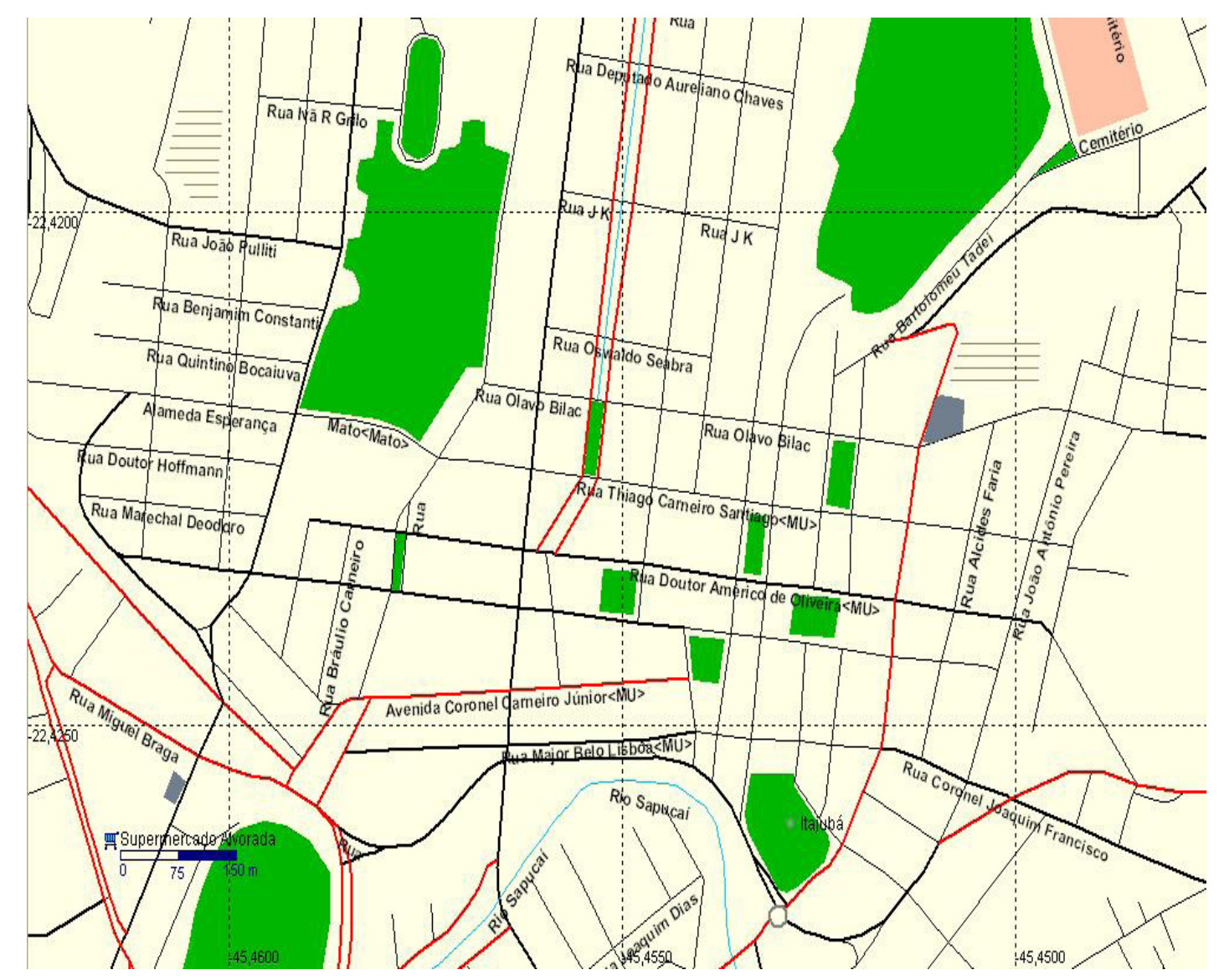

Figura 1 - Vetorização 




Figura 2 - Complemento de atributos

Outro ponto a se destacar é o fato de que a escolha de quais dados tabulares devem constar no mapa é diretamente relacionada ao propósito da aplicação onde o mapa será utilizado. Como o propósito nesse caso é o auxílio à navegação veicular rodoviária, o projeto contemplou dados como: nomenclatura e classificação das vias, velocidade das mesmas, mãos de direção etc.

A padronização dos atributos a persistirem no mapa é outro fator que culmina na qualidade final do mapa e por isso é previsto no documento de padrão do projeto.

\subsection{HIERARQUIA}

A hierarquia é fundamental para permitir a roteirização sobre o mapa, pois dela depende a qualidade dos mapas para a navegação e, conseqüentemente, das rotas que serão traçadas no aparelho GPS.

Tal processo consiste em definir o peso de cada via para o processo de roteirização, a fim de indicar as vias mais apropriadas na criação de rotas. Toda cidade deve ter uma malha principal e uma secundária. A primeira é composta pelas vias de alta hierarquia conectadas entre si è̀s rodovias que cortam a cidade, formando uma espécie de esqueleto da cidade, sendo independente da malha secundária, que é formada por ruas de menor fluxo.

Assim, ao se criar uma rota, a malha principal ganha prioridade, e a rota sempre que possível permanecerá nela, só trafegando fora quando necessário, como no início ou no fim do percurso. A maioria das ruas é considerada como secundária, $\mathrm{e}$ as de maior fluxo, dependendo da intensidade deste, são promovidas a níveis de hierarquia mais altos, como ruas primárias ou avenidas.

Os algoritmos de roteirização usam diversos critérios para a escolha das vias que farão parte da rota: velocidade, pavimento, número de pistas, trânsito, comprimento, áreas do entorno, POIs do entorno etc. $\mathrm{O}$ mapeamento colaborativo nem sempre consegue contemplar todos esses critérios, devido a complexidade, volume e acesso aos dados a serem coletados.

Mesmo assim, deve-se tentar ao máximo completar estes atributos pelo menos para as vias de alta hierarquia, para se garantir a criação de uma 
rota com o máximo de informações pertinentes e facilidades para o usuário. A Figura 3 apresenta a malha principal da cidade de Itajubá-MG, onde linhas pretas representam ruas primárias e linhas vermelhas representam avenidas.

\subsection{MÃO DE DIREÇÃO E OUTRAS RESTRIÇÕES}

É possível definir as direções das vias, a fim de se ter restrições de conversão para as rotas. Para tanto, direciona-se a rua para o lado de seu fluxo e adiciona-se uma TAG ao nome da rua, o que permitirá ao GPS reconhecer automaticamente a via como de fluxo unilateral, e levará tal informação em consideração quando for criar rotas.

Caso a rua já se encontre direcionada corretamente, deve-se apenas adicionar $<\mathrm{MU}>$ após o nome da via, caso contrário pode-se modificar a TAG para $<M U=-1>$. Existem outros tipos de restrições, cada qual com sua respectiva TAG. Exemplos são: classe da via, velocidade, presença de pedágios e restriçōes de tráfego por tipo de veículo, como carros, ônibus, bicicletas, caminhões e pedestres.

\subsection{PONTOS DE INTERESSE}

Outro ponto importante é a adição de Pontos de Interesse (POI). Estes POI's permitem ao usuário localizar rapidamente seu destino caso deseje chegar em algum destes pontos, ou usar o POI como referência. Os principais pontos que devem ser adicionados são Hospitais, Rodoviárias, Bancos, Restaurantes, Escolas e Universidades, Supermercados, dentre outros.

Os POI's devem ser adicionados ao lado da via mais próxima à sua localização, tendo o cuidado de não sobrepor a via, e deve-se sempre utilizar o padrão do projeto para identificar estes pontos. $O$ padrão indica qual o símbolo que se deve utilizar para determinado ponto e indica se o ponto precisa ter comentários, como no caso de postos de combustível, nos quais é necessário indicar qual sua bandeira junto ao nome.

\subsection{BUSCA POR ERROS / CONTROLE DE QUALIDADE}

Existem também programas auxiliares desenvolvidos exclusivamente para o projeto que ajudam a garantir a correta formatação do mapa. Programas como Validador e Conversor são utili- zados para indicar erros, sendo que para um mapa ser analisado pelo conversor, deve ter passado pelo validador e ter seus erros corrigidos.

Exemplos de erros são proximidade de nós, sobreposição e duplicação de vias, nomes de vias que não condizem com o padrão, indicação de tracks que não pertençam aos limites do município desenvolvido, indicação de polígonos (como praças, por exemplo) que estejam incorretos, dentre outros. Em suma, os erros ligados ao desenho das vias ou formatação incorreta serão indicados por um destes programas. A Figura 4 exemplifica um destes programas auxiliares, o conversor.

\subsection{ENVIO PARA COMPILADOR}

Uma vez que o mapa passou por todas as fases descritas anteriormente, ele deve ser enviado ao desenvolvedor estadual, que é um voluntário com a função de compilar os mapas enviados pelos desenvolvedores municipais e disponibilizar estes mapas para todos.

Este desenvolvedor, também chamado de compilador, tem a função de verificar se os mapas estão corretos, podendo recusá-los, caso encontre dados fora do padrão de formatação ou fora das fronteiras do mapa. O mapa pode ser enviado através do site do projeto, sendo que o envio é função do desenvolvedor municipal.

\subsection{DOWNLOAD DOS MAPAS}

Os mapas, depois de prontos, podem ser encontrados na página do projeto na Internet, disponíveis para qualquer usuário. $\mathrm{O}$ usuário apenas precisa localizar, através de uma lista, em qual conjunto se encontra o mapa desejado e então deve fazer o download do conjunto, sendo que serão instalados todos os mapas (municipais e estaduais) que estiverem no arquivo.

Uma vez localizado o mapa, a transferência para o GPS é simples, bastando conectar o aparelho ao computador e selecionar no menu "GPS", disponível no GTM, qual o aparelho utilizado. Feito isso, deve-se selecionar a opção de envio e qual informação deve ser enviada, se trilhas, pontos, rotas ou mesmo tudo.

\subsection{ATUALIZAÇÃO DO MAPA}

Após completada a compilação das vias, como é o caso do mapa de Itajubá, o mapa pode 


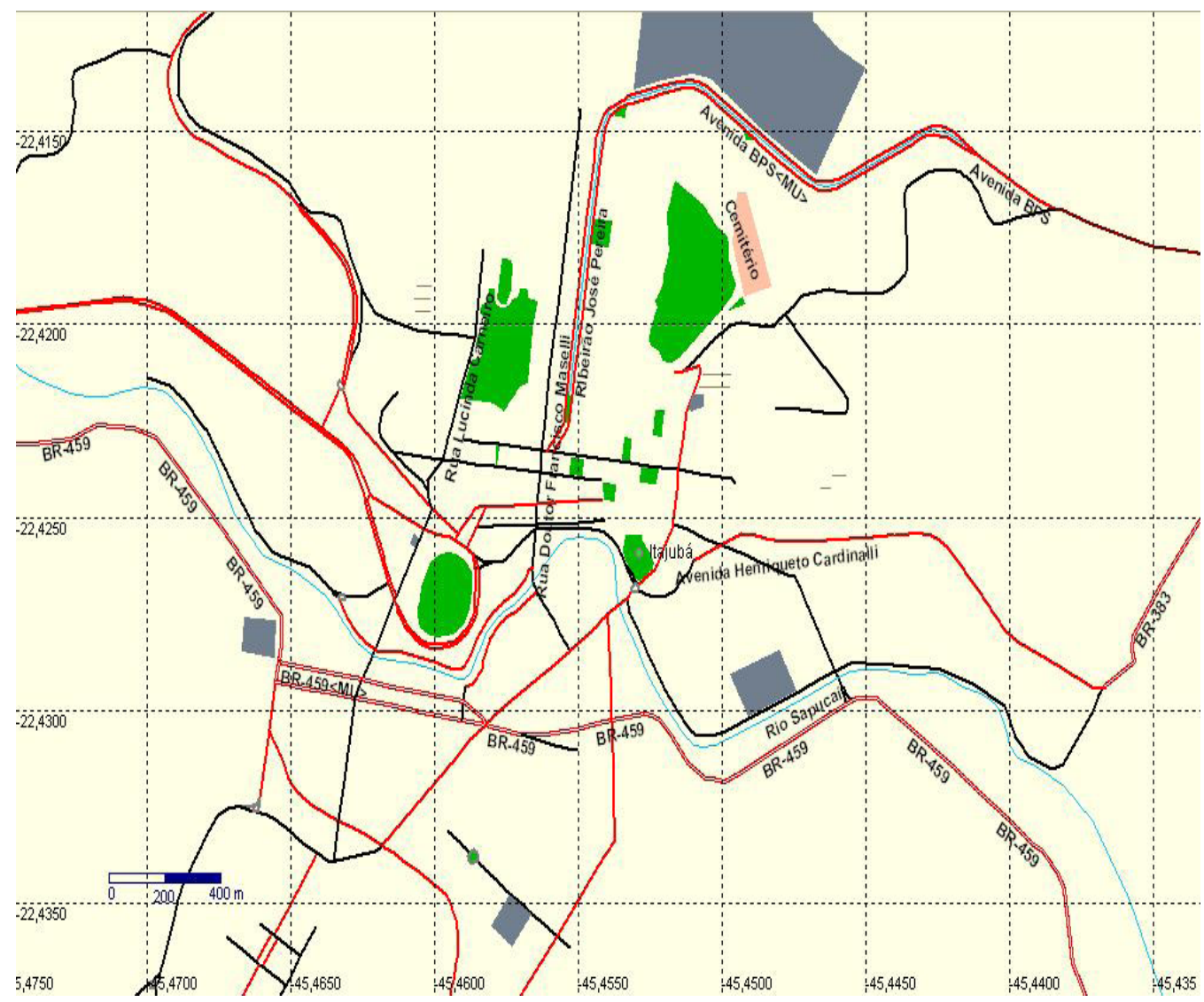

Figura 3 - Hierarquia de vias

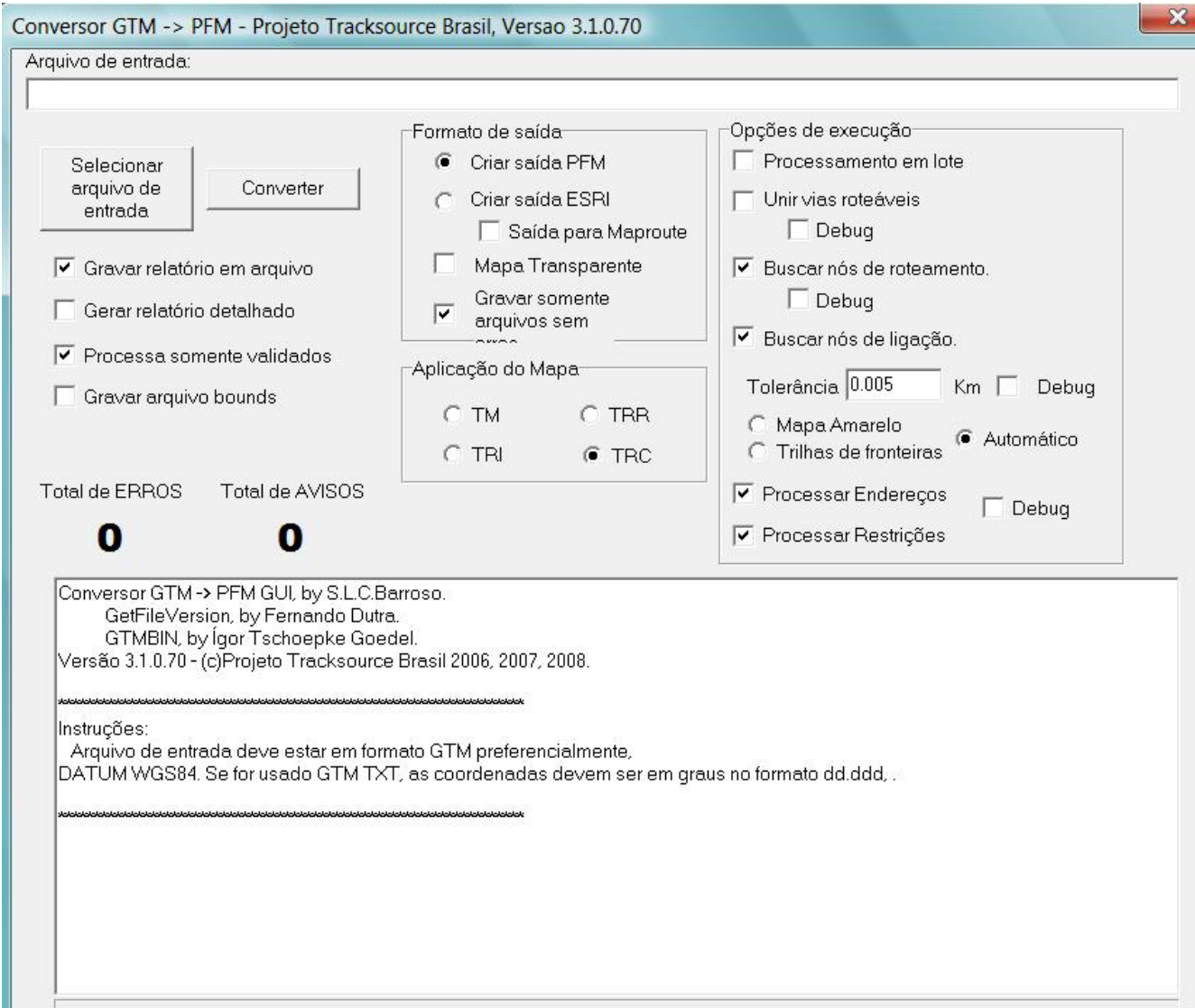

Figura 4 - Conversor 
ser considerado disponibilizado, mas nenhum mapa do Projeto Tracksource é considerado finalizado, visto que todos os mapas podem ser atualizados, com freqüência mensal.

Essas atualizações podem incorporar novas vias, novos pontos de interesse, novas estradas de terra, atualizações de mão de direção, hierarquia de vias e qualquer outra informação do mapa, que podem ser obtidas por novos levantamentos de dados do desenvolvedor ou contribuiçôes recebidas de outros voluntários.

\section{CONCLUSÔES}

O resultado específico do presente trabalho se concretiza na inclusão do município de ItajubáMG na compilação do mapa rodoviário e urbano de todo o Brasil, disponível gratuitamente no site do Projeto Tracksource.

Uma vez que o objetivo do trabalho foi ilustrar como o mapeamento colaborativo pode ser utilizado para a obtenção de um mapa digital para aplicações em transportes, pode-se afirmar que a participação no projeto foi fundamental para estudar o mecanismo da colaboração entre seus participantes.

Através dessa experiência foi possível identificar os pilares do mapeamento colaborativo, quais fatores sustentam a qualidade do mapa, e quais partes da estrutura estão mais suscetíveis a erros e resultados indesejados. A orientação dos manuais, a utilização das ferramentas do projeto e o apoio da comunidade de voluntários, permitiram que o levantamento do mapa fosse realizado de forma eficiente.

Quanto ao auxílio prestado no sentido da gestão do projeto para os voluntários constata-se que a orientação é enxuta e suficiente para a orientação dos desenvolvedores voluntários. Esse fato é indispensável para se ter o retorno esperado: dados mapeados compatíveis. Nesse sentido não foram encontradas grandes dificuldades para chegar ao mapa dentro dos padrões do projeto, tornando a experiência bem sucedida tanto para o voluntário que visa seu próprio levantamento, quanto para os gestores do projeto e usuários finais que visam a composição final.

Outro fato notado é que o esforço para elaboração do mapa foi substancialmente menor se comparado ao trabalho individual e isolado desde o mapeamento até a publicação do mapa fora dos padrōes do projeto. Assim, o mapeamento colaborativo e suas diretrizes compilam o conhecimento útil para iniciantes que precisam mapear determinada área.

Dessa forma, a decisão de participar do projeto não ocorre apenas com o propósito de contribuir com a iniciativa: o interessado pode utilizar os padróes do projeto para guiar sua coleta e atender sua necessidade e então, conseqüentemente, beneficiar muitos outros usuários disponibilizando seus mapas que já estarão conforme os padrões da colaboração.

As diretrizes e padronizações propostas pelo projeto, ao serem adotadas pelos usuários de mapas colaborativos, tornam os dados bastante acessíveis e práticos, justamente por construir um referencial compreendido por todos.

Além disso, a documentação didática do know-how de como se mapear torna atrativa a idéia de ser um colaborador e amplia o mapeamento em todo o país. Esse fato traduz o resultado geral do trabalho: a apresentação de uma fonte alternativa para se obter dados de infra-estrutura de Transporte no Brasil. Dessa forma, o mapeamento colaborativo se mostra como fonte sólida e não apenas uma tendência passageira.

O mapa gerado através do mapeamento colaborativo tem um propósito bem definido, orientação para navegação veicular. Assim, é conveniente uma análise mais específica sobre a eficácia na utilização desses mapas em outros contextos. Uma vez que os mapas do Projeto TrackSource estão disponíveis no site do projeto, os dados podem ser adquiridos pela internet e posteriormente convertidos e transferidos para o aparelho GPS, via softwares específicos.

Através do software GTM, é possível gerar arquivos no formato KML com os mapas do projeto, formato de arquivo digital bastante comum entre os SIG comerciais, possibilitando ointercâmbio de dados. Há também a possibilidade de conversão para arquivos do tipo shape (SHP). Dessa forma, o mapeamento colaborativo contempla mais do que os navegadores veiculares, oferecendo mapas viários aptos a serem utilizados em aplicações de transportes em diversos SIG comerciais.

Finalmente, pode-se afirmar que o mapeamento colaborativo é uma opção concreta para obtenção de mapas digitais para aplicações em transportes, especialmente num país como o Brasil, com dimensôes continentais e com defasagem na disponibilização pública desse tipo de informação. 
O número de municípios já mapeados, o número de visitas ao site do Projeto TrackSource, os acessos internacionais aos dados disponibilizados, as ferramentas que surgem na internet estimulando sugestôes de melhoria de mapas por qualquer internauta, o surgimento e consolidação de iniciativas e projetos como o TrackSource, todos esses fatores vem a sugerir que o mapeamento colaborativo é uma tendência sólida para o levantamento de dados espaciais.

\section{AGRADECIMENTOS}

Os autores agradecem ao $\mathrm{CNPq}$ (Conselho Nacional de Desenvolvimento Científico e Tecnológico) e a FAPEMIG (Fundação de Amparo à Pesquisa do Estado de Minas Gerais), pelo apoio financeiro concedido a diversos projetos que subsidiaram o desenvolvimento desse trabalho.

\section{REFERÊNCIAS BIBLIOGRÁFICAS}

CUNHA, C.B. Aspectos Práticos da Aplicação de Modelos de Roteirização de Veículos a Problemas Reais. Transportes, v. 8, n. 2, p. 51-74, 2000.

CHARLIER, F.; QUINTALE, C.J. O SIG como ferramenta de gestão ambiental em uma ferrovia. Revista ENGEVISTA, v. 6, n. 3, p. 25-35, dezembro 2004.

DAVIS JUNIOR, C.A.; FONSECA, F.T.; CÂMARA, G. Infraestruturas de dados espaciais na integração entre ciência e comunidades para promover a sustentabilidade ambiental. In: I Workshop de Computação Aplicada à Gestão do Meio Ambiente e Recursos Naturais, Bento Gonçalves, 2009.

ENOMOTO, L.M. e LIMA, R.S. Análise da distribuição física e roteirização em um atacadista. Produção (São Paulo), v. 17, p. 94-108, 2007.

FERREIRA, E.; DANTAS, A.A.A.; CARVALHO, M.A. Avaliação da área e do entorno da Represa de Furnas, possibilidades e tendências. In: XIII Simpósio Brasileiro de Sensoriamento Remoto, Florianópolis, 2007.

LIMA, P.; CÂMARA, G.; PAIVA, J.A.; MONTEIRO, A.M.V. Intercâmbio de Dados Geográ- ficos: Modelos, Formatos e Conversores. In: III Simpósio Brasileiro de Geoinformática,GeoInfo, Rio de Janeiro, 2001.

LIMA, R.S.; PONS, N.A.D.; LIMA, J.P. Precisão aceitável? A utilização do Google Earth para obtenção de mapas viários urbanos para SIG. Revista Infogeo, v. 57, p. 34-36, 2009.

MAPA, S.M.S.; LIMA, R.S.; MENDES, J.F.G. Combining Geographic Information Systems (GIS) and mathematical modeling to location-allocation problems in education facilities management. In: X CUPUM, International conference on computers in urban planning and urban management, Foz do Iguaçu, 2007.

MARTONI, R.M.; VARAJÃO, G.F.D.C. Sistema de Posicionamento Global no Turismo: aplicações, MG, por meio de SIG utilizando dados públicos: facilidades, dificuldades e problemas. Anais do XIII Simpósio Brasileiro de Sensoriamento Remoto, Florianópolis, p. 879-886, 2008.

SANTOS, M.Y.C.A. PADRÃO - Um Sistema de Descoberta de Conhecimento em Bases de Dados Geo-referenciadas. X p. Tese (Doutorado em Tecnologias e Sistemas de Informação) - Universidade do Minho, 2001. Disponível em <http://hdl.handle.net/1822/202>. Acesso em 13 de jul. 2009.

SEGANTINE, P.C.L. Sistema Global de Posicionamento - GPS. São Carlos: Escola de Engenharia de São Carlos - EESC/USP. 364 p, 2005.

Tracksource (2009). Projeto Tracksource: Mapas gratuitos para o Brasil. Disponível em <http://www. tracksource.org.br>. Acesso em: 16 maio, 2010.

VALLADARES, G.S.; FARIA, A.L.L. SIG na análise do Risco de Salinização na bacia do Rio Coruripe, AL. Revista ENGEVISTA, v. 6, n. 3, p. 86-98, dezembro 2004.

VINHAS, L. Um subsistema extensível para o armazenamento de geo-campos em banco de dados geográficos. 337 p. (INPE-14167-TDI/1084). Tese (Doutorado em Computação Aplicada) Instituto Nacional de Pesquisas Espaciais, São José dos Campos, 2006. Disponível em: <http:// www.dpi.inpe.br/-lubia/TeseLubia.pdf>. Acesso em: 14 jul. 2009. 